\title{
Preventing fungal growth on heritage paper with antifungal and cellulase inhibiting magnesium oxide nanoparticles
}

Isabel Franco Castillo, ${ }^{a, b}$ Esther García Guillén, ${ }^{c}$ Jesús M. de la Fuente, ${ }^{a, b}$ Filomena Silva, ${ }^{\text {d,e }}{ }^{\text {Scott } G .}$ Mitchell ${ }^{\text {a,b }}$

Microorganisms such as bacteria, fungi, algae and moulds are highly proficient at colonizing artistic and architectural heritage. The irreparable damage they cause to unique artefacts results in immeasurable cultural and societal losses to our shared cultural heritage, which represent an important social and economic resource for Europe. With the overall aim of preventing fungal deterioration of paper artefacts, we report the use of magnesium oxide nanoparticles (MgO NPs) of average diameter $12 \mathrm{~nm}$ as potent antifungal agents against fungi commonly found colonising paper heritage: A. niger, C. cladosporioides and T. reesei. Dispersions of MgO NPs on original $18^{\text {th }}$ century paper samples from the Archives of the Spanish Royal Botanic Garden were effective at preventing fungal colonisation without altering the appearance of the paper artefacts. Importantly, MgO NPs also inhibit cellulase activity in the filamentous fungi $T$. resei and $A$. niger, two of the principle biodeteriogens of cellulosic materials. In addition, our report provides three simple new proceedures for studying the fungal colonisation prevention properties of nanomaterials on paper samples. Overall this opens the door to the use of colourless, low-cost, and scalable nanomaterials for preventing biodeterioration in cellulose-based artefacts.

\section{Introduction}

Much of our shared tangible cultural heritage is based on paper objects: from books and documents, to maps, paintings, drawings and other works of art. ${ }^{1}$ The organic composition of paper-based heritage artefacts means that they are highly susceptible to irreversible biodeterioration - "any undesirable change in the properties of a material caused by the vital activities of organism". 2,3 Protecting and preserving such heritage from colonisation by microorganisms is therefore a matter of great importance. ${ }^{4,5}$

Filamentous fungi are considered to be some of the most hazardous microorganisms for cultural heritage objects, ${ }^{6}$ and cellulolytic fungi are particularly harmful for paper objects. ${ }^{7,8}$ Fungi not only affect aesthetic aspects of the object or artefact, resulting in effects such as foxing or discoloration; they also produce organic acids and degrading enzymes, such as cellulases or proteases, ${ }^{9}$ which damage the structural integrity of the object. $^{10}$ During cellulose degradation, the hydrolysis of glycosidic bonds and oxidation of glucopyranose rings results in the formation of acids which further catalyse paper degradation by breaking cellulose chains, transforming the paper into a delicate and brittle object. The Trichoderma and Aspergillus genera are two prolific cellulase producers that often threaten paper heritage. ${ }^{11,12}$ Furthermore, certain fungi that are often found colonizing museum spaces, archives and libraries - such as those from Aspergillus, Fusarium and Penicillium may be dangerous to professionals and visitors alike due to the production of mycotoxins, which can be inhaled causing immune system issues and allergic diseases, mycotoxicosis and organ mycoses. ${ }^{13-17}$

To combat paper degradation, conservators and restorers use a variety of different methods that have been changing radically in recent years. ${ }^{18}$ Ethanol $(70 \%)$ is one of the most effective short-term disinfectant solutions, ${ }^{19}$ nonetheless a typical spray application, which is common and convenient for restorers, does not remove all types of microorganisms and recolonization is frequent. ${ }^{20}$ Over the last century chemical agents such as quaternary ammonium salts, ethylene oxide, alcohols or formaldehyde have been used to disinfect objects. $^{21,22}$ However, potent antifungal compounds like these pose a direct risk to human health due to their high overall cytotoxicity. For example ethylene oxide, which is a carcinogenic and mutagenic gas, can cause severe allergic reactions. ${ }^{23,24}$ One widely used and effective physical method is gamma radiation, which kills fungi and their spores; however, the required fungicidal doses are higher than those needed for bactericidal action. ${ }^{25}$ Moreover, this radiation can affect the cellulose fibres and paper structure and important health and safety consideration must also be given to the operator. ${ }^{8}$ As a result, new potent antifungal treatments that are simultaneously safe to human health must be developed.

To this end, restorers have frequently turned to using aqueous calcium hydroxide or calcium carbonate ${ }^{26}$ solutions to neutralize acids and simultaneously serve as a local alkali reserve to prevent further colonization to prevent the degradation of historical paper. During the last decade, nanoparticles (NPs) as nanosols, alcohol dispersions and powders have been used to prevent the degradation of paper, stone, paintings and wood heritage. ${ }^{27,28}$ NPs provide an alternative to other common antimicrobials, and their effectiveness lies in their ability to interact with DNA and proteins and pass through the cell membrane. ${ }^{29,30}$ One of the most widely used are silver nanoparticles (Ag NPs), ${ }^{31,32}$ which offer high antimicrobial properties at low concentrations and multiple mechanisms of action (e.g. Ag inhibits the replication of DNA, disrupts respiratory processes and disturbs the electrical potential of the cell membrane, among others) ${ }^{32-34} \mathrm{Ag}$ NPs are used commercially as active ingredients in health, cosmetics and packaging due to their multifunctional mode of action, broad 
spectrum antibacterial activity and the unlikelihood of development of resistance. ${ }^{35}$ Nevertheless, silver is toxic to cells of higher animals ${ }^{36}$ and can disturb the ecological balance in natural systems. ${ }^{37}$ Furthermore, from a heritage conservation perspective, highly coloured noble metal particles present their own limitations. Other nanoparticles alternative include nanostructured zinc oxide $(\mathrm{ZnO})$, which is antibacterial and antifungal activity but bio-safe and bio-compatible, as well as the nanometric form of $\mathrm{TiO}_{2}$, which is characterized by its broadspectrum biocidal activity and low cytotoxicity. ${ }^{38,39}$ However, the photocatalytic antimicrobial activity of nano$\mathrm{TiO}_{2}$ means that it is light dependent, and loses its effectiveness in environments with limited or no UV light ${ }^{30}$ and it has been found to be less effective against fungi than against bacteria or viruses. ${ }^{40}$

The advantages of these nanostructured inorganic materials resides in their tuneable physicochemical properties and modular nature, which allow us to obtain a library of materials with different sizes, shapes and surface properties. ${ }^{41,42}$ In the context of paper conservation, the high surface area of nanoparticles means that they can effectively cover paper and penetrate into the network of cellulose fibres to neutralize acids and protect paper from cellulose hydrolysis. Currently, the most common analytical techniques used to study the antimicrobial properties of NPs on heritage surfaces are based on optical and electron microscopies and colourimetry, but these methods are limited and do not characterise the medium-to-long-term influence of antimicrobial nanoparticles. ${ }^{43}$

Here we present a combination of three rapid procedures to comprehensively characterise the antifungal properties and biodeterioration prevention activity of nanomaterials for heritage paper conservation. We have demonstrated these using magnesium oxide nanoparticles (MgO NPs) as antifungal agents to prevent the fungal colonization of a variety of $18^{\text {th }}$ century paper samples from the Archives of the Spanish Royal Botanic Garden in Madrid (Spain). Although there have been several studies concerning the antibacterial activity of MgO NPs, their exact mechanism is still unknown. Different antibacterial mechanisms have been proposed, such as the formation of reactive oxygen species (ROS) and non-ROS mediated interaction with the cell wall or the cell membrane of the bacteria as well as an alkaline effect due to the increase of the $\mathrm{pH}$ mediated by the MgO NPs. ${ }^{41,44,45}$ However, their antifungal activity has not been comprehensively reported in the literature. In this report the antifungal activity of MgO NPs has been studied against three different moulds that frequently contaminate heritage paper: Aspergillus niger (genera Aspergillus represents 29\%), Cladosporium cladosporioides (genera Cladosporium represents 5-7\%) and Trichoderma reesei (genera Trichoderma represents $4 \%) .{ }^{4} A$. niger causes black stains due to the production of melanin. ${ }^{46,47}$ It is particularly harmful to paper because of its ability to grow on substrates with low (7-8\%) moisture content, ${ }^{48}$ and it is an important producer of cellulase, an enzyme capable of degrading cellulose fibres into glucose. ${ }^{12} \mathrm{C}$. cladosporioides affects paper by producing melanoidines which cause stains ${ }^{47,49}$ and $T$. reesei is one of the most prominent cellulaseproducing fungi triggering irreparable damage to cellulose containing heritage objects. ${ }^{11,50}$

\section{Results and discussion}

Magnesium oxide nanoparticles (MgO NPs) were synthesised by a sol-gel method and used as antifungal agents on $18^{\text {th }}$ century heritage paper samples. The $12 \mathrm{~nm}$ diameter MgO NPs were prepared using a sol-gel synthesis ${ }^{51}$ according to our previously reported experimental procedure, ${ }^{52}$ which provided sufficient control of the nanoparticle size and morphology (Figure 1). Further characterization of the nanoparticles can be found in our previous report. ${ }^{52} \mathrm{MgO}$ NPs are particularly interesting due to their low cost and environmental friendly characteristics. ${ }^{53}$ They possess antibacterial properties resulting from two proposed mechanisms of action: one mediated by the production of reactive oxygen species (ROS), which induces oxidative stress and lipid peroxidation in bacteria, ${ }^{44}$ and non-ROS mediated mechanisms. ${ }^{54}$ Cell viability assays have demonstrated the absence of cytotoxicity of these nanoparticles. ${ }^{52,55}$

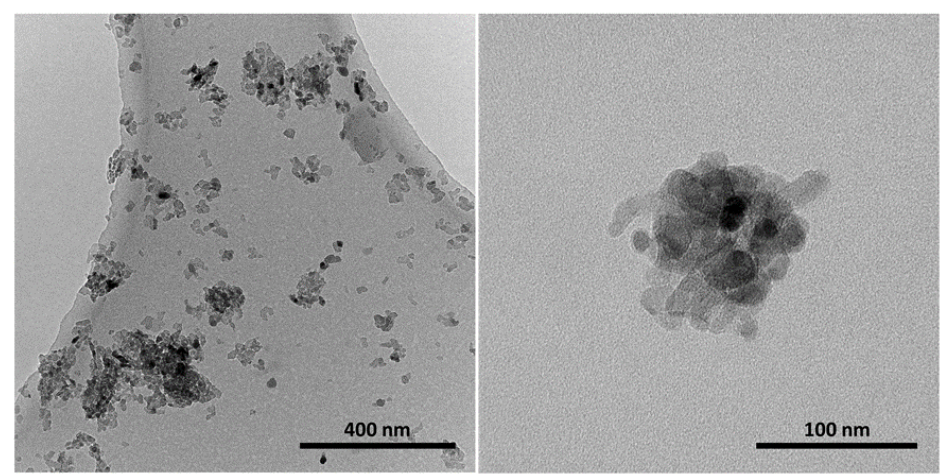

Figure 1. TEM images of magnesium oxide nanoparticles (MgO NPs) ca. $12 \mathrm{~nm}$ diameter prepared by sol-gel synthesis. 
Three representative fungal strains, Aspergillus niger ( $A$. niger), Cladosporium cladosporioides (C. cladosporioides) and Trichoderma reesei ( $T$. reesei), were chosen based on their prevalence in heritage artefacts and their cellulose degradation activity. $4,11,46,49$ The antifungal activity of MgO NPs was determined using an antifungal broth microdilution assay to determine the minimal inhibitory concentration (MIC) values of NPs that are able to inhibit fungal growth. ${ }^{56} \mathrm{C}$. cladosporioides was the most resistant to MgO NPs with a MIC value of $12 \mathrm{mg} / \mathrm{mL}$, followed by $A$. niger $(6 \mathrm{mg} / \mathrm{mL})$; whereas $T$. reesei proved to be the most susceptible to $\mathrm{MgO}$ NPs, with the lowest MIC value equal to $3 \mathrm{mg} / \mathrm{mL}$ (Table 1 ).

Table 1. MgO NP minimum inhibitory concentration (MIC) values against $A$. niger, $C$. cladosporioides and T. reesei.

\begin{tabular}{cccc} 
& \multicolumn{3}{c}{ Fungal species } \\
\hline & A. niger & $\begin{array}{c}\text { C. } \\
\text { cladosporioides }\end{array}$ & T. reesei \\
\hline $\begin{array}{c}\text { MIC value } \\
(\mathrm{mg} / \mathrm{mL})\end{array}$ & 6 & 12 & 3
\end{tabular}

Given the in vitro antifungal activity that was observed, a series of assays were designed to evaluate the in situ activity of the MgO NPs on original $18^{\text {th }}$ paper samples from the Archives of the Spanish Royal Botanic Garden (CSIC) in Madrid (Figure S1). In total, three different in situ antifungal procedures were designed to establish the antifungal mode of action of the MgO NPs on paper samples and gain insight into longevity of action. The homogeneity of the MgO NPs coating was studied by Environmental Scanning Electron Microscopy (Figure S2) and the amount of MgO NPs coating the papers was quantified by Inductively Coupled Plasma Mass Spectrometry (ICP-MS). The $18^{\text {th }}$ century papers coated with a MgO NP solution were found to contain $0.86 \mathrm{mg}$ of $\mathrm{Mg}$ per $\mathrm{g}$, while the amount of $\mathrm{Mg}$ on the untreated paper samples was found to be $77 \mu \mathrm{g}$ per $\mathrm{g}$

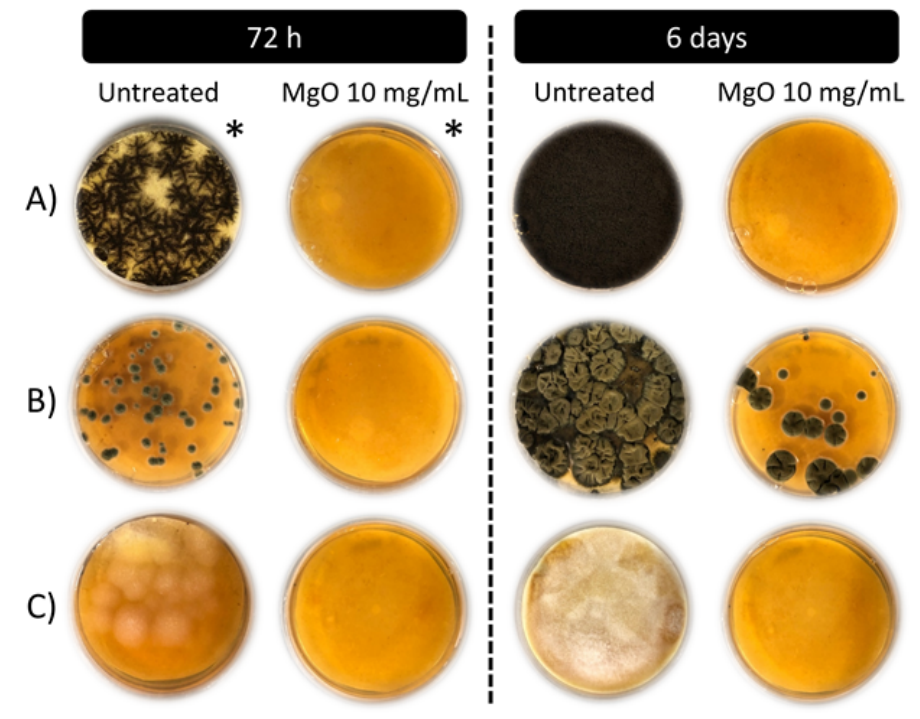

(Figure S3).

Figure 2. Antifungal activity of MgO NPs against A. niger (A), C. cladosporioides (B) and T. reesei (C) on paper samples under optimal growth conditions after $72 \mathrm{~h}\left({ }^{*} 48 \mathrm{~h}\right.$ for $A$. niger) and 6 days of incubation.

For the first antifungal assay performed in heritage paper samples, $5 \mathrm{~cm}$ diameter circles were coated with an aqueous dispersion of $\mathrm{MgO}$ NPs $(10 \mathrm{mg} / \mathrm{mL})$. This concentration was selected to ensure a satisfactory antifungal activity based on the MIC values for the fungal strains. Once dry, the paper samples were covered with a thin Sabouraud Dextrose Agar (SDA) layer and incubated at their optimum growth temperatures for six days. As observed in Figure 2, after 72 hours of incubation ( ${ }^{*} 48 \mathrm{~h}$ for $A$. niger), fungal growth is clearly visible in the control samples, while no growth was observed in paper samples treated with MgO NPs. After longer incubation times of up to six days, $A$. niger and $T$. reesei failed to display any growth (fungicidal action), however $C$. cladosporioides began to proliferate on the MgO NP treated samples. Given that the MgO NPs were applied at $10 \mathrm{mg} / \mathrm{mL}$ and the MIC value for the $C$. cladosporioides is $12 \mathrm{mg} / \mathrm{mL}$, a fungistatic action was not obtained, leading to the initiation of fungal growth after six days.

The antifungal activity was also evaluated in situ, where $2 \times 2 \mathrm{~cm}$ sterile paper samples were coated with 10 $\mathrm{mg} / \mathrm{mL} \mathrm{MgO}$ NPs and incubated in a humidity chamber. Fungal growth was monitored by macroscopic inspection of paper samples as well as microscopic observation (Environmental Scanning Electron Microscopy (ESEM) and optical microscopy). The brown-black fungal growth of $A$. niger and C. cladosporioides was easily observed in the untreated samples while T. reesei presented a yellow coloured growth (Figure 3 and Figure S4). 
The images obtained by optical microscopy (Figure S5) and ESEM (Figure 3 and Figure S6) confirmed that the untreated paper samples were covered with fungi mycelium for all three moulds, with a significant amount of spores in the case of $A$. niger, while MgO NP treated paper samples showed no fungal growth over the paper surface and only cellulose fibres were observed (Figure 3). From these two in situ assays we can conclude that MgO NPs deposited on the $18^{\text {th }}$ century paper samples at $10 \mathrm{mg} / \mathrm{mL}$ are capable of inhibiting the fungal growth of the selected fungi, with a fungicidal action against $A$. niger and $T$. reesei (the two cellulose producing strains responsible for paper degradation) and a fungistatic action against $C$. cladosporoides.

A. niger and T. reesei are both producers of cellulase, an enzyme responsible for catalysing cellulolysis, the decomposition of cellulose and related polysaccharides into simple monosaccharides for energy purposes. Fungal growth on artefacts made from cellulosic materials can undergo rapid and severe biodeterioration as the colonizing microbes consume cellulose for energy. Consequently, the third and final assay was designed to assess the adhesion of fungal cells to the paper samples and evaluate the cellulose prevention capacity of the MgO NPs on heritage paper samples. The MgO NP concentration dependent fungal cell adhesion to the paper was evaluated by incubating different concentrations of MgO NP treated paper samples (1/4, 1/2, 1x and 2x the MIC value) with $A$. niger and $T$. reesei. By weighing the papers after the incubation with the fungi, their adhesion to the papers and subsequent growth can be determined by comparing the dry weight of the positive control papers (incubated without MgO NPs) with the dry weight of the MgO NP-treated papers (Figure S7). Figure 4 reports how the MgO NPs inhibit the adhesion and growth of $A$. niger and $T$. reesei at concentrations lower than the MIC value. At the lowest MgO NP concentration (1/4 MIC), both fungi are capable of growing on papers, but at concentrations greater than $1 / 2 \mathrm{MIC}$, fungal adhesion and growth are highly diminished and even completely inhibited.

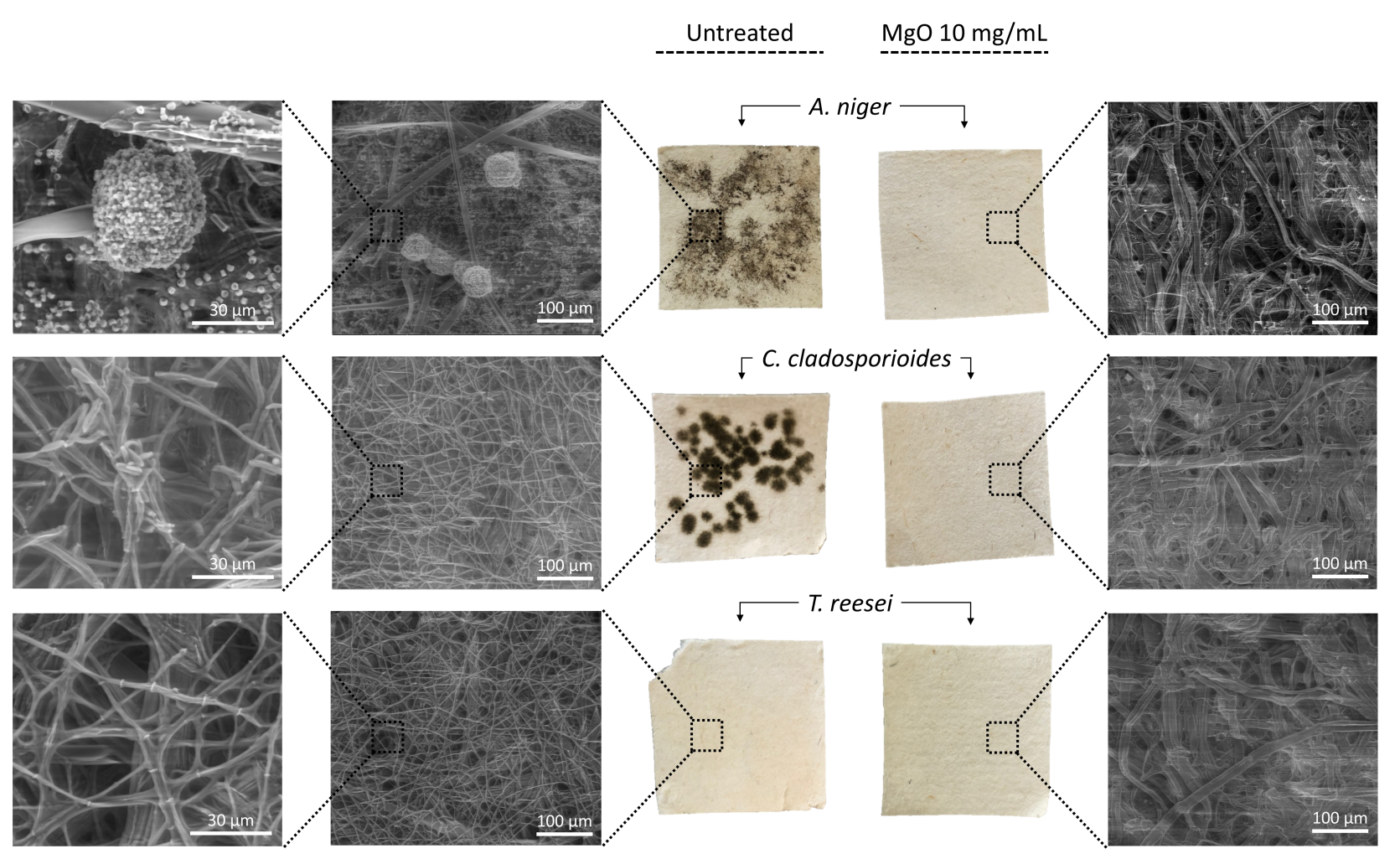

Figure 3. In situ antifungal activity of MgO NPs. The untreated papers (left) present fungal growth visible by the naked eye and confirmed by ESEM imaging, where the growth of all three fungal strains ( $A$. niger, C. cladosporioides and $T$. reesei) are clearly observable on top of the cellulose fibres of the untreated papers, but are absent from the MgO NP treated papers (right).

The anticellulase activity of the MgO NPs was analysed by incubating the particles with commercial $A$. niger and $T$. reesei cellulase extracts. Cellulase activity decreased with increasing MgO NP concentration, where concentrations of $1 / 2$ MIC were able to reduce the cellulase enzymatic activity by half, with only residual enzymatic activity being observed at the MIC concentration for each fungal strain (Figure 5). 


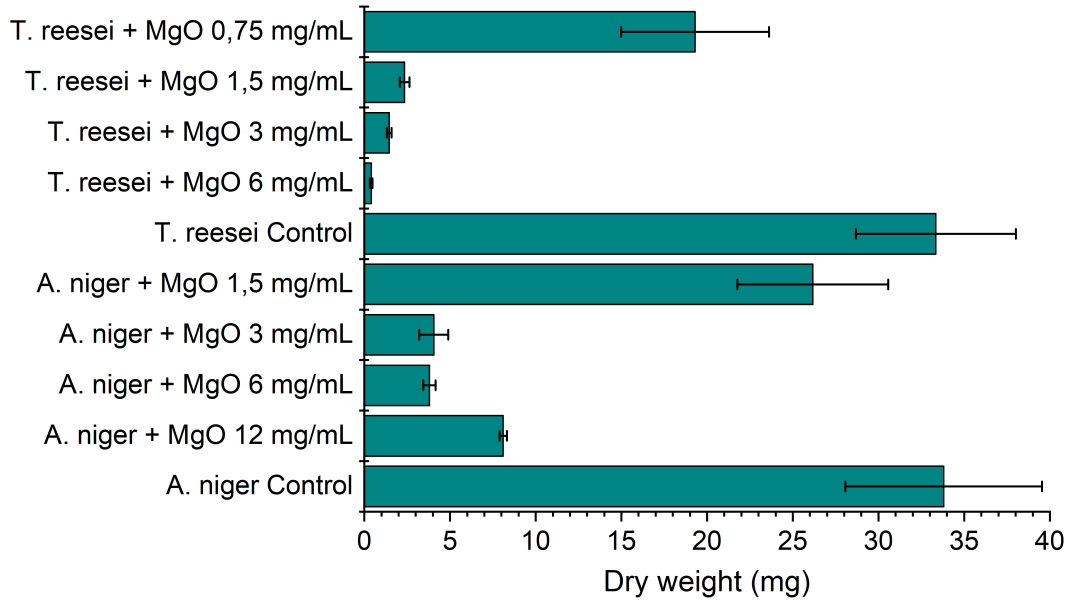

Figure 4. Mean dry weight of the paper samples (error bars correspond to SD values of three independent assays) incubated with $A$. niger and $T$. reesei in presence of MgO NPs. The MgO NPs inhibit fungal growth and adhesion to the paper at $3 \mathrm{mg} / \mathrm{mL}$ for $A$. niger and at $1.5 \mathrm{mg} / \mathrm{mL}$ for $T$. reesei (concentrations that are equal to $1 / 2$ of the MIC of MgO NPs for each fungal strain).

A) A. niger cellulase activity inhibition by MgO NPs

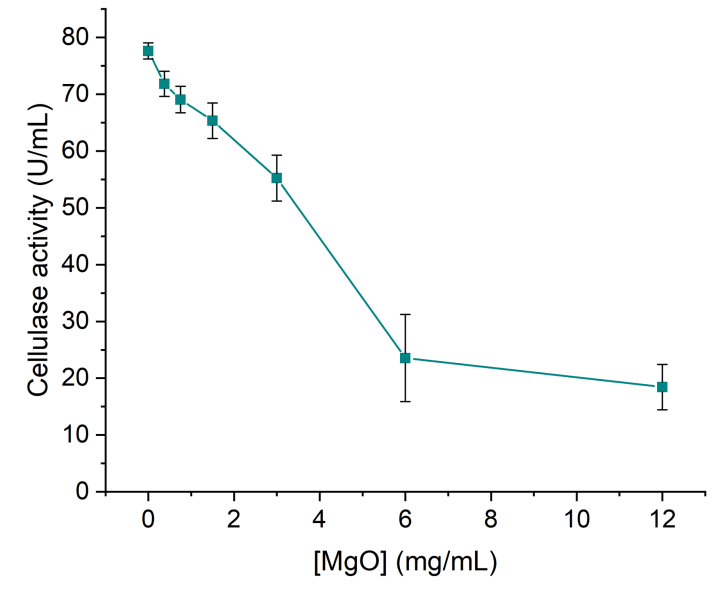

B) T. reesei cellulase activity inhibition by MgO NPs

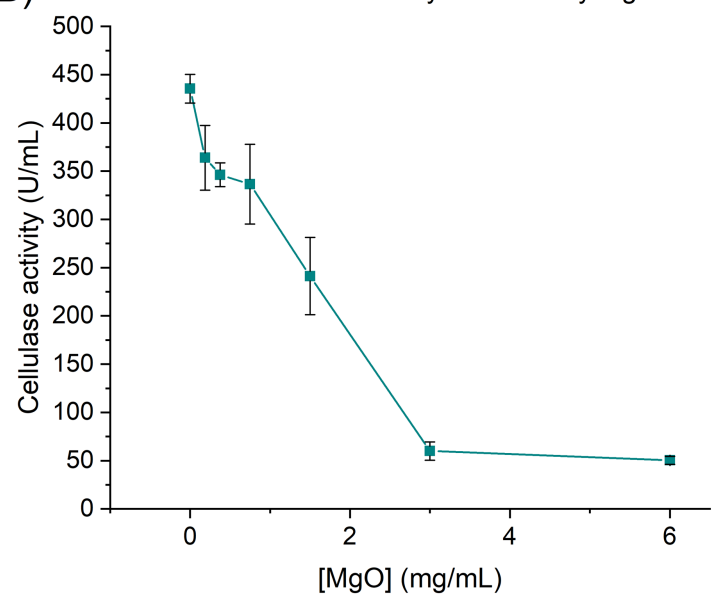

Figure 5. Enzymatic activity of cellulase from $A$. niger $(A)$ and $T$. reesei $(B)$ incubated with $M g O N P$ s at concentrations of $1 / 16,1 / 8,1 / 4$, $1 / 2,1 x$ and $2 x$ the corresponding MIC values for each fungus. Error bars correspond to SD values of three independent assays.

To confirm that the $\mathrm{MgO}$ nanoparticles were not visibly altering the appearance of the paper samples, colorimetric measurements were performed before and after the MgO NP coating. As shown in Figure 6, the 
MgO NP coating did not produce any significant changes in the luminosity $(\Delta \mathrm{L})$ or colour $(\Delta \mathrm{E})$. The $\Delta \mathrm{E}$ mean value was 2.55 , which is far below the $\Delta \mathrm{E}$ limit value where chromatic changes become visible to the naked eye $(\Delta \mathrm{E}=5) .{ }^{57}$

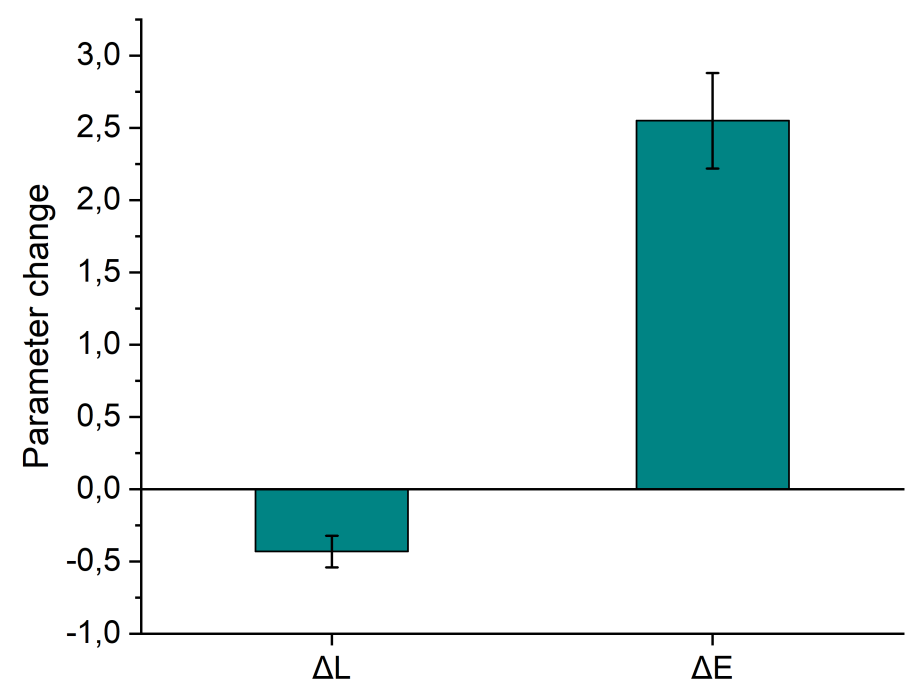

Figure 6. Luminosity change $(\Delta \mathrm{L})$ and colour change $(\Delta \mathrm{E})$ of the paper samples after coating with the $10 \mathrm{mg} / \mathrm{mL} \mathrm{MgO}$ NP dispersion.

\section{Conclusions}

In this research we have demonstrated how cheap, colourless and scalable dual-functional magnesium oxide nanoparticles (MgO NPs) can be used to protect original heritage papers from fungal biodeterioration via antifungal and cellulose inhibition. In vitro studies showed that the small $12 \mathrm{~nm}$-diameter MgO NPs possessed fungistatic activity against three filamentous fungal strains, $T$. reesei $A$. niger and $C$. cladosporioides, at concentrations between 3 and $12 \mathrm{mg} / \mathrm{mL}$. A series of in situ antifungal studies were developed to confirm the antifungal properties of the MgO NPs on original $18^{\text {th }}$ century paper samples. A homogenous $10 \mathrm{mg} / \mathrm{mL}$ dispersion of MgO NPs provided complete inhibition of all three fungal strains while simultaneously avoiding any unwanted colour changes to the paper. Importantly, the fungal adhesion to the paper was inhibited at MgO NP concentrations as low as $1.5 \mathrm{mg} / \mathrm{mL}$ for $T$. reesei and $3 \mathrm{mg} / \mathrm{mL}$ and for $A$. niger. Furthermore, the MgO NPs inhibit $A$. niger and $T$. reesei cellulase enzymes, meaning that these nanoparticles prevent degradation of the cellulose fibres as well as fungal colonization. These results illustrate how a combination of rapid antifungal procedures and high-resolution environmental electron microscopy techniques can be used to comprehensively characterise the biodeterioration prevention properties of nanomaterials and pave the way for the rapid screening of other potential antifungal nanomaterials for heritage conservation.

\section{Experimental}

Reagents. Magnesium methoxide, $7-8 \%$ in methanol (Alfa-Aesar); absolute ethanol (PanReac AppliChem); Cellulase extract from $T$. reesei and A. niger, Sigmacell cellulose; 3,5-Dinitrosalicylic acid (DNS), 2,3,5Triphenyltetrazoliumchlorid (XTT), Menadione, Sodium cacodylate trihydrate, Sucrose, Glutaraldehyde $25 \%$ and $\mathrm{NaCl}$ (all from Sigma-Aldrich).

Test papers. $18^{\text {th }}$ century paper samples were obtained from the leftovers of the Herbarium sheets conserved in the Archives of the Real Jardín Botánico (CSIC) in Madrid, Spain.

Microorganisms and growth conditions. Two moulds from the Colección Española de Cultivos Tipo (CECT) were tested in the antifungal assays: Aspergillus niger CECT 2088, Cladosporium cladosporioides CECT 2111. Trichoderma reesei RUT C-30 was kindly provided by the CICS-UBI - Health Sciences Research Centre, University of Beira Interior, Portugal. Fungal spore suspensions were stored in $0.1 \%$ Tween, $20 \%$ glycerol at $-80^{\circ} \mathrm{C}$ prior to use. Before each assay, fungal cells were inoculated in SDA plates and slants (Sabouraud Dextrose Agar (supplemented with chloramphenicol, Scharlab, S.L.) and grown at $35^{\circ} \mathrm{C}$ for 5 days. 
For the fungal adhesion assays, the following liquid medium was used: $2.0 \mathrm{~g} / \mathrm{L} \mathrm{KH}_{2} \mathrm{PO}_{4} ; 1.4 \mathrm{~g} / \mathrm{L}\left(\mathrm{NH}_{4}\right)_{2} \mathrm{SO}$; $0.0027 \mathrm{~g} / \mathrm{L} \mathrm{FeSO} \cdot 7 \mathrm{H}_{2} \mathrm{O} ; 0.0016 \mathrm{~g} / \mathrm{L} \mathrm{MnSO}_{4} \cdot \mathrm{H}_{2} \mathrm{O} ; 0.0014 \mathrm{~g} / \mathrm{L} \mathrm{ZnSO} \cdot \mathrm{H}_{2} \mathrm{O} ; 0.0037 \mathrm{~g} / \mathrm{L} \mathrm{CoCl}_{2} \cdot 6 \mathrm{H}_{2} \mathrm{O} ; 0.6 \mathrm{~g} / \mathrm{L}$ $\mathrm{MgSO}_{4} \cdot 7 \mathrm{H}_{2} \mathrm{O} ; 0.4 \mathrm{~g} / \mathrm{L} \mathrm{CaCl} 2 \cdot 2 \mathrm{H}_{2} \mathrm{O} ; 0.75 \mathrm{~g} / \mathrm{L}$ peptone; $2.0 \mathrm{~g} / \mathrm{L}$ Tween $80 ; 0.3 \mathrm{~g} / \mathrm{L}$ urea; and $5 \mathrm{~g} / \mathrm{L}$ glucose in formate buffer $50 \mathrm{mM} \mathrm{pH}=4.8$. $^{58}$

\section{Methods}

Environmental Scanning Electron Microscopy (ESEM). Data were collected on a Quanta FEG-250 (FEI Company) field emission SEM for high-resolution imaging working in ESEM mode using a GSED detector under high relative humidity conditions.

Fungi proliferation assay. Fungal growth was recorded by measuring the optical density (OD) of the samples at $620 \mathrm{~nm}$ after 48 of incubation using a microplate reader (Thermo Scientific MULTISKAN GO). A XTT assay was performed to confirm the results, measuring the absorbance at $450 \mathrm{~nm}$ using a microplate reader (Thermo Scientific MULTISKAN GO). Results were compared with the OD variation of a control culture containing only fungi. The assays were replicated four times and the modal value was chosen as the Minimal Inhibitory Concentration (MIC).

Transmission Electron Microscopy (TEM). Magnesium oxide nanoparticles (MgO NP) were resuspended in ethanol under sonication and visualized by Bright Field (BF) imaging in a FEI Tecnai T20 microscope operating at $200 \mathrm{kV}$. More than $100 \mathrm{NPs}$ were measured and an estimation of the diameter has been obtained using Digital Micrograph ${ }^{(G a t a n}$ Inc., Pleasanton, TX, USA) and OriginLab® (OriginLab, Northampton, MA, USA).

Nanoparticle synthesis. MgO nanoparticles were synthesized by sol-gel method through a modification of protocols already reported in literature ${ }^{52}$ Briefly, $7.2 \mathrm{~mL}$ of magnesium methoxide, $\mathrm{Mg}\left(\mathrm{OCH}_{3}\right)_{2},(4.8 \mathrm{mmol})$ were added to $40 \mathrm{~mL}$ of absolute ethanol under ultrasonication and subsequently $1.8 \mathrm{~mL}$ of water (100 mmol) were added to the mixture. The sol was sonicated for 30 minutes and then kept for $36 \mathrm{~h}$ under gentle stirring to facilitate gelification. The water/ethanol gel suspension was heated in an oil bath under a progressive increase of the temperature from 70 to $90{ }^{\circ} \mathrm{C}$ during a period of $5 \mathrm{~h}$. Then a fine magnesium dihydroxide powder was obtained by evaporating the solvent and finally this $\mathrm{Mg}(\mathrm{OH})_{2}$ powder was completely oxidised to $\mathrm{MgO}$ by heating at $600{ }^{\circ} \mathrm{C}$ for 30 minutes. Yield=120 mg (dry particles).

Inductively coupled plasma mass spectrometry (ICP-MS). The amount of MgO NPs on the paper after the coating was analysed by ICP-MS. $1 \times 1 \mathrm{~cm}$ squares of $18^{\text {th }}$ century paper were coated with $10 \mathrm{mg} / \mathrm{mL} \mathrm{MgO} \mathrm{NPs}$ solution (uncoated samples were used as a control). All the paper samples were digested in $100 \mu \mathrm{L}$ of piranha solution for 15 minutes at room temperature and then $300 \mu \mathrm{L}$ of aqua regia were added and incubated for 2 hours at room temperature followed by 15 minutes at $60{ }^{\circ} \mathrm{C}$. Afterwards, the samples were diluted in Milli- $Q$ water to a final volume of $20 \mathrm{~mL}$. ICP-MS measurements were carried out with a quadrupole Agilent 7500 series ICP-MS instrument (Agilent Technologies, CA, USA), equipped with a Babington nebulizer and a double pass spray chamber. Magnesium quantification was performed using a calibration curve ranging from 1 and $1000 \mathrm{ng} / \mathrm{g}(\mathrm{ppb}) \mathrm{Mg}(\mathrm{I})$ in ultra-pure water. The data acquisition parameters for both calibration curve and samples were set to the single particle mode for detecting the presence of magnesium $\left({ }^{24} \mathrm{Mg},{ }^{25} \mathrm{Mg}\right.$, and $\left.{ }^{26} \mathrm{Mg}\right)$, in a full quantitative mode, with 1 point per spectral peak, an integration time of $0.2 \mathrm{~s}$ per point and 10 repeats per sample, giving a total acquisition time of $40.2 \mathrm{~s}$. Digested paper and paper with MgO NPs samples were measured in triplicate and quintuplicate, respectively. The control paper samples were diluted $1 / 10$ and the MgO coated paper samples were diluted $1 / 100$ to adjust the concentration to the calibration curve.

Fungi growth inhibition assay. The determination of the minimum inhibitory concentration of MgO NPs was performed using a broth microdilution method according to the EUCAST guidelines (E.DEF 9.3.1). ${ }^{56}$ The experiments were performed with three moulds, A. niger, C. cladosporioides and $T$. reesei. Fungi spores were incubated for five days in SDA plates at $35^{\circ} \mathrm{C}$ for $A$. niger and $T$. reesei and at $25^{\circ} \mathrm{C}$ for $C$. cladosporioides. By picking the aerial part of the fungi, a suspension of $10^{6}$ conidia/mL was prepared in sterile water with $0.1 \%$ Tween. This suspension was diluted to $10^{5}$ conidia/mL in distilled sterile water and added to a 96 well plate to a final concentration of $5 \times 10^{4}$ conidia/mL. Geometric two-fold dilutions of MgO NPs [0.09375, 0.1875, 0.375, 0.75, $1.5,3,6,12 \mathrm{mg} / \mathrm{mL}$ ] were made by dispersing them in RPMI and sonicated for 30 minutes before adding them to the 96 well-plate. Positive control contained only fungal inocula and culture media while the negative control contained only MgO NPs dispersed in culture medium. After an incubation period of $48 \mathrm{~h}$, at $35^{\circ} \mathrm{C}$ for $A$. niger and $T$. reesei and at $25^{\circ} \mathrm{C}$ for $\mathrm{C}$. cladosporioides, according to CECT recommendations, the minimum inhibitory concentration (MIC) values were determined as the lowest $\mathrm{MgO}$ concentration able to inhibit fungal growth detectable to the naked eye. MIC values were further confirmed by measuring the $\mathrm{OD}_{620}$ and fungal metabolic 
activity using XTT and menadione. The colorimetric assay based on XTT was carried out by adding $50 \mu \mathrm{L}$ of saline containing $1 \mathrm{mg}$ of $\mathrm{XTT} / \mathrm{mL}$ and $20.2 \mu \mathrm{g}$ of menadione/mL (previously dissolved in acetone at a concentration of $430 \mu \mathrm{g} / \mathrm{mL}$ and then diluted $1 / 10$ in saline) was added to each well to obtain a final concentration of $200 \mu \mathrm{g}$ of $\mathrm{XTT} / \mathrm{mL}$ and $4.3 \mu \mathrm{g}$ of menadione/mL $(25 \mu \mathrm{M})$. Following an incubation period of $2 \mathrm{~h}$ in the dark to allow conversion of the XTT to its formazan derivative, the absorbance at $450 \mathrm{~nm}$ was measured.

\section{Antifungal assays on paper samples}

Antifungal activity under optimal growth conditions. The $18^{\text {th }}$ century paper samples were cut in $5 \mathrm{~cm}$ diameter discs and sterilized by autoclaving. After drying, sterilized papers were placed into a $5.5 \mathrm{~cm}$ Petri dish and impregnated with $800 \mu \mathrm{L}$ of a $10 \mathrm{mg} / \mathrm{mL}$ MgO NPs solution in sterile distilled water. The papers were allowed to dry at room temperature and the $\mathrm{MgO}$ impregnation protocol was repeated to ensure a homogeneous coating. When the papers were completely dry, $500 \mu \mathrm{L}$ of a fungi inoculum $\left(10^{3}\right.$ conidia $/ \mathrm{mL}$, in distilled water) was added to the coated papers and over a positive growth control paper sample without MgO NPs. Then, SDA culture media was added until the paper was completely covered. Plates were incubated at $35^{\circ} \mathrm{C}$ for $A$. niger and $T$. reesei and at $25^{\circ} \mathrm{C}$ for $\mathrm{C}$. cladosporioides. The fungal growth was monitored for 6 days.

In situ antifungal activity. The $18^{\text {th }}$ century paper samples were cut in $2 \times 2 \mathrm{~cm}$ squares and sterilized by autoclaving. Sterile paper samples were placed into a 6 well plate and impregnated with $100 \mu \mathrm{L} \mathrm{of} \mathrm{a} 10 \mathrm{mg} / \mathrm{mL}$ MgO NP solution (dissolved in RPMI) using a micropipette. The papers were let to dry and the impregnation protocol was repeated to ensure a homogeneous coating. When the papers were completely dry, $100 \mu \mathrm{L}$ of a fungi inoculum $\left(10^{3}\right.$ conidia/mL in RPMI) was added to the coated papers and over a positive growth control paper sample without MgO NPs. Afterwards, plates were incubated in a humidity chamber at the respective temperature for each fungus. Fungal growth was monitored during 2 weeks. In order to visualize the samples with ESEM, the papers were washed with $2 \mathrm{~mL}$ of saline and fixed with a $2 \mathrm{~mL}$ of cacodylate buffer $0.1 \mathrm{M}$ for $1 \mathrm{~h}$ and 30 minutes at $37{ }^{\circ} \mathrm{C}$. Then the samples were dehydrated with methanol ( 5 min with methanol $30 \%, 5$ min with methanol 50\%, 5 min with methanol 70\%, 10 min with methanol 100\% and 5 min with methanol 100\%) and kept at room temperature for further analysis.

Inhibition of fungal adhesion. $18^{\text {th }}$ century paper samples were incubated in $10 \mathrm{~mL}$ fermentation medium containing $1 \mathrm{~mL}$ of an $A$. niger and $T$. reesei inoculum $\left(10^{5}\right.$ conidia/mL, prepared in liquid medium) and $\mathrm{MgO}$ NPs at the 1/4, 1/2, 1x and 2x MIC value which corresponds to the following concentrations: $1.5,3,6,12 \mathrm{mg} / \mathrm{mL}$ for $A$. niger and $0.75,1.5,3,6 \mathrm{mg} / \mathrm{mL}$ for $T$. reesei. Three paper samples of $1 \times 3 \mathrm{~cm}$ were used for each sample, in addition with a positive growth control sample without MgO NPs and a negative control without fungi. Samples were incubated four days at $35^{\circ} \mathrm{C}$ with agitation. After incubation, paper samples were removed from the culture, washed with sterile saline solution and dried at $50{ }^{\circ} \mathrm{C}$ until a constant weight was achieved.

Cellulase activity. Cellulase extracts from $A$. niger and $T$. reesei were incubated with different MgO NPs concentrations $(1 / 16,1 / 8,1 / 4,1 / 2,1 \mathrm{x}$ and $2 \mathrm{x} \mathrm{MIC})$ for $1 \mathrm{~h}$ at $37^{\circ} \mathrm{C}$ with agitation. After incubation, $1 \mathrm{~mL}$ of cellulase solutions was mixed with $4 \mathrm{~mL}$ of a cellulose $5 \%(\mathrm{w} / \mathrm{v})$ solution and incubated at $37{ }^{\circ} \mathrm{C}$ for $120 \mathrm{~min}$ with vigorous stirring to determine the cellulase activity. All the reagents were prepared in $50 \mathrm{mM}$ sodium acetate buffer $\mathrm{pH}$ 5. Cellulase activity, expressed as enzymatic units (one unit (U) will liberate $1.0 \mu$ mole of glucose from cellulose in one hour at $\mathrm{pH} 5$ at $37^{\circ} \mathrm{C}$ ), was determined by quantifying the release of reducing sugars produced after the incubation period as reported in the DNS method, using glucose as standard. ${ }^{59}$

Colorimetric measurements. Colour changes of the $18^{\text {th }}$ century papers after the coating with a $10 \mathrm{mg} / \mathrm{mL}$ MgO NPs solution (in distilled water) was measured with a Chroma Meter CR-400 (Konica Minolta) during 4 days post-application of the MgO NP coating. Measurements were performed on two paper samples $(4 \times 4 \mathrm{~cm})$ before and after the coating, measuring five points for each paper to account for sample heterogeneity. The result of the chromatic change $(\Delta E)$, given by the three colorimetric coordinates $\left(L^{*}, a^{*}, b^{*}\right)$, was determined by the following equation:

$$
\Delta \mathrm{E}=\sqrt{\Delta L^{2}+\Delta a^{2}+\Delta b^{2}}
$$

\section{Conflicts of interest}

There are no conflicts to declare. 


\section{Acknowledgements}

Financial support by the Fundación General CSIC (SGM, Programa ComFuturo) and Fondo Social EuropeoGobierno de Aragón is gratefully acknowledged. IFC acknowledges the Gobierno de Aragón for a doctoral scholarship (2018-2022). The authors thank prof. Fernanda Domingues from the Health Sciences Research Centre, Portugal for providing T. reesei RUT C-30 strain. The authors also wish to thank The Advanced Microscopy Laboratory (Universidad de Zaragoza) for access to their instrumentation and expertise. The authors would like to thank Dr. Jesús Salafranca for his assistance with the ICP-MS measurements.

\section{References}

C. Roman, R.-M. Diaconescu, L. Scripcariu and A. Grigoriu, Eur. J. Sci. Theol., 2013, 9, 263-271.

M. Area and H. Cheradame, Bioresources, 2011, 6, 5307-5337.

D. Allsopp, K. J. Seal, C. C. Gaylarde, D. Allsopp, K. J. Seal and C. C. Gaylarde, Introd. to Biodeterior., 2010, 13-14.

D. Melo, S. O. Sequeira, J. A. Lopes and M. F. Macedo, J. Cult. Herit., 2019, 35, 161-182.

Off. J. Eurpean Union, 2014, 183, 36-38.

M. L. Coutinho, A. Z. Miller, A. Phillip, J. Mirão, L. Dias, M. A. Rogerio-Candelera, C. Saiz-Jimenez, P. M. MartinSanchez, L. Cerqueira-Alves and M. F. Macedo, Constr. Build. Mater., 2019, 212, 49-56.

A. A. Fabbri, A. Ricelli, S. Brasini and C. Fanelli, Int. Biodeterior. Biodegrad., 1997, 39, 61-65.

K. Sterflinger, Fungal Biol. Rev., 2010, 24, 47-55.

H. Arai, Int. Biodeterior. Biodegrad., 2000, 46, 181-188.

A. B. Strzelczyk, Int. Biodeterior. Biodegrad., 2004, 53, 151-156.

F. C. Domingues, J. A. Queiroz, J. M. S. Cabral and L. P. Fonseca, Enzyme Microb. Technol., 2000, 26, 394401.

R. P. de Vries and J. Visser, Microbiol. Mol. Biol. Rev., 2001, 65, 497-522.

N. Mesquita, A. Portugal, S. Videira, S. Rodríguez-Echeverría, A. M. L. Bandeira, M. J. A. Santos and H. Freitas, Int. Biodeterior. Biodegrad., 2009, 63, 626-629.

K. F. Nielsen, Fungal Genet. Biol., 2003, 39, 103-117.

B. Gutarowska, M. Sulyok and R. Krska, Indoor Built Environ., 2010, 19, 668-675.

B. Gutarowska, M. Kosmowska, M. Wiszniewska, C. Pałczyński and J. Walusiak-Skorupa, Indoor Built Environ., 2012, 21, 253-263.

S. López-Aparicio, J. Smolík, L. Mašková, M. Součková, T. Grøntoft, L. Ondráčková and J. Stankiewicz, Build. Environ., 2011, 46, 1460-1468.

S. O. Sequeira, E. J. Cabrita and M. F. Macedo, Restaurator, 2014, 35, 181-199.

S. O. Sequeira, A. J. L. Phillips, E. J. Cabrita and M. F. Macedo, Stud. Conserv., 2017, 62, 33-42.

M. Nittérus, Restaurator, 2000, 21, 101-115.

F. H. Hengemihle, N. Weberg and C. Shahani, Preserv. Res. Test. Ser. No. 9502.

W. A. Rutala and D. J. Weber, J. Hosp. Infect., 1999, 43, S43-S55.

M. S. Rakotonirainy, F. Fohrer and F. Flieder, Int. Biodeterior. Biodegradation, 1999, 44, 133-139.

M. S. Rakotonirainy and B. Lavédrine, Int. Biodeterior. Biodegradation, 2005, 55, 141-147.

M. Nittérus, Restaurator, 2000, 21, 25-40.

G. Poggi, N. Toccafondi, L. N. Melita, J. C. Knowles, L. Bozec, R. Giorgi and P. Baglioni, Appl. Phys. A, 2014, 114, 685-693.

R. Giorgi, M. Baglioni, D. Berti and P. Baglioni, Acc. Chem. Res., 2010, 43, 695-704.

G. Poggi, N. Toccafondi, D. Chelazzi, P. Canton, R. Giorgi and P. Baglioni, J. Colloid Interface Sci., 2016, 473, 1-8.

L. Wang, C. Hu and S. Longquan, Int. J. Nanomedicine, 2017, 12, 1227-1249.

B. O. Ortega-Morales, M. M. Reyes-Estebanez, C. C. Gaylarde, J. C. Camacho-Chab, P. Sanmartín, M. J. ChanBacab, C. A. Granados-Echegoyen and J. E. Pereañez-Sacarias, Adv. Mater. Conserv. Stone, 2018, $277-298$. J. S. Kim, E. Kuk, K. N. Yu, J.-H. Kim, S. J. Park, H. J. Lee, S. H. Kim, Y. K. Park, Y. H. Park and C.-Y. Hwang, Nanomedicine Nanotechnology, Biol. Med., 2007, 3, 95-101.

M. Rai, A. Yadav and A. Gade, Biotechnol. Adv., 2009, 27, 76-83.

Q. L. Feng, J. Wu, G. Q. Chen, F. Z. Cui, T. N. Kim and J. O. Kim, J. Biomed. Mater. Res., 2000, 52, 662-668.

I. Sondi and B. Salopek-Sondi, J. Colloid Interface Sci., 2004, 275, 177-182.

X. Zhang, H. Niu, J. Yan and Y. Cai, Colloids Surfaces A Physicochem. Eng. Asp., 2011, 375, 186-192.

Y.-H. Hsin, C.-F. Chen, S. Huang, T.-S. Shih, P.-S. Lai and P. J. Chueh, Toxicol. Lett., 2008, 179, 130-139.

S. A. Blaser, M. Scheringer, M. MacLeod and K. Hungerbühler, Sci. Total Environ., 2008, 390, 396-409. 

17-22.

S. A. Ruffolo, M. F. La Russa, M. Malagodi, C. Oliviero and A. M. Palermo, Appl. Phys. A, 2010, 100, 829-834. Z.-X. Tang, X.-J. Fang, Z.-L. Zhang, T. Zhou, X.-Y. Zhang and L.-E. Shi, Brazilian J. Chem. Eng., 2012, 29, 775781.

D. Pinna, B. Salvadori and M. Galeotti, Sci. Total Environ., 2012, 423, 132-141.

Z.-X. Tang and B.-F. Lv, Brazilian J. Chem. Eng., 2014, 31, 591-601.

N. Y. T. Nguyen, N. Grelling, C. L. Wetteland, R. Rosario and H. Liu, Sci. Rep., 2018, 8, 1-23.

T. R. Jørgensen, J. Park, M. Arentshorst, A. M. van Welzen, G. Lamers, R. A. Damveld, C. A. M. van den Hondel, K. F. Nielsen, J. C. Frisvad and A. F. J. Ram, Fungal Genet. Biol., 2011, 48, 544-553.

D. C. de Melo, Universidade Nova de Lisboa, 2017.

O. S. G. Caneva, M. Nugari, Biology in the Conservation of Works of Art, Rome, 1991.

D. E. Eveleigh, Appl. Microbiol., 1970, 19, 872.

R. Peterson and H. Nevalainen, Microbiology, 2012, 158, 58-68.

R. Mbarki, A. Mnif and A. H. Hamzaoui, Mater. Sci. Semicond. Process., 2015, 29, 300-306.

I. Franco Castillo, L. De Matteis, C. Marquina, E. García, J. Martínez de la Fuente and S. G. Mitchell, Int. Biodeterior. Biodegrad., 2019, 141, 79-86.

N. Salehifar, Z. Zarghami and M. Ramezani, Mater. Lett., 2016, 167, 226-229.

Y. H. Leung, A. M. C. Ng, X. Xu, Z. Shen, L. A. Gethings, M. T. Wong, C. M. N. Chan, M. Y. Guo, Y. H. Ng, A. B. DjuriA ic, P. K. H. Lee, W. K. Chan, L. H. Yu, D. L. Phillips, A. P. Y. Ma and F. C. C. Leung, Small, 2014, 10, 1171-1183. 9.3.1)., , DOI:10.2134/agronj2016.07.0440.

57 I. D. Van der Werf, N. Ditaranto, R. A. Picca, M. C. Sportelli and L. Sabbatini, Herit. Sci., 2015, 3, 1-9.

58 S. M. P. Ferreira, A. P. Duarte, J. A. Queiroz and F. C. Domingues, Electron. J. Biotechnol., 2009, $12,1-9$.

59 G. L. Miller, Anal. Chem., 1959, 31, 426-428. 